\title{
Assessment of Spatial and Temporal Pattern of Hydrological Droughts in the Upper Indus Basin, Pakistan
}

\author{
Muhammad Saifullah", 2*, Shiyin Liu²*, Muhammad Adnan², Muhammad Zaman ${ }^{3}$, \\ Sher Muhammad ${ }^{4}$,Muhammad Babur5, Yu Zhu', Kunpeng Wu²
}

\footnotetext{
${ }^{1}$ Department of Agricultural Engineering, Muhammad Nawaz Shareef University of Agriculture, Multan 66000, Pakistan

${ }^{2}$ Institute of International Rivers and Eco-Security, Yunnan University, Kunming 650500, China

${ }^{3}$ Department of Irrigation and Drainage, University of Agriculture, Faisalabad 380000, Pakistan

${ }^{4}$ International Centre for Integrated Mountain Development (ICIMOD), GPO Box 3226, Kathmandu, Nepal

${ }^{5}$ Department of Civil Engineering, Faculty of Engineering, University of Central Punjab, Lahore 54000, Pakistan
}

Received: 1 November 2020

Accepted: 20 January 2021

\begin{abstract}
The current study used a threshold approach to determine the number of drought events, scarcity, their mean and maximum duration whereas New Innovative Trend analysis (ITA) was used to determine the spatio-temporal pattern of hydrological drought from 1961 to 2010. The results revealed a trendless pattern of scarcity at Dainyor station excluding extreme pattern which increased significantly whereas the mild pattern of water scarcity was observed at Gilgit station which was found to be increased significantly while other factors of hydrological drought were found trendless. The extreme pattern of water scarcity was found to be increased at Garhi Habibullah station whereas the scarcity pattern increased significantly at Naran station. Overall, the extreme pattern of scarcity increased considerably in the UIB. A significant increase in the maximum duration of drought events and an insignificant increase in the extreme pattern of the maximum duration of the drought was observed at Naran. Though, it was observed an increase in the mild pattern of maximum duration at Dainyor whereas a decrease at Gilgit. However, the maximum duration pattern decreased significantly at Garhi Habibullah. All other patterns of maximum duration occurred in the trendless region.
\end{abstract}

Keywords: hydrological drought, upper indus basin, new innovative trend pattern, threshold, Pakistan

\footnotetext{
*e-mail: saif_2146@yahoo.com
}

*e-mail: shiyin.liu@ynu.edu.cn 


\section{Introduction}

Drought is one of the most destructive and widespread natural disasters [1, 2]. Mostly hydrological drought is recorded due to a significantly lower level of hydrological variables than normal [3]. Drought significantly disturbs the hydrological cycle and the streamflow observed lower than the normal levels of the region [4]. Drought has a negative impact on agriculture, community, ecology, economy, and politics [5]. Many studies have been conducted around the world to investigate the drought pattern in North America [6], Amazon basin [7], South Korea [8], Nigeria [9], Canada [10]. Droughts-prone disasters have become a rising challenge in different parts of the world like Africa [11], East and South parts of Asia during 1960-2010 [12]. [13] determined the complex influences of meteorological drought time-scales on hydrological droughts. A hydrological drought index (the Standardized Streamflow Index; SSI) was linked to the Standardized Precipitation Evapotranspiration Index (SPEI) to evaluate the drought severity. Overall, it was observed a positive response of SSI to SPEI at shorter time-scales for natural basins adjoining the United States. Similarly, [14] used standardized precipitation, water level, and runoff indexes to monitor the drought in the Vistula basin Poland. Another, study conducted by [15] determined the agricultural-related drought risks through satellite images in Ukraine. The eastern countries of Asia including China have suffered more from extreme droughts as compared to the rest of the world [16, 17]. A significant portion of Bangladesh was affected by drought during the Kharif Season and the highest return period for moderate and severe categories of droughts were observed in this region [18]. Similarly, climate change has also increased the frequency of meteorological droughts in Malaysia [19]. However, the moderate drought and wet events in India were found to be relatively more than that of severe and extreme droughts [20]. The drought hazardous index showed an inverse relationship with precipitation and elevation and it increased with low elevation and precipitation [21]. Droughts are becoming common in the future due to climate change [22, 23], which emphasizes on understanding the patterns of droughts severity, and duration [24]. Drought events had also been perceived in India during July 2002 [25]. Indus River passes through the territory of India, Pakistan, and China. Streamflow in the Upper Indus Basin (UIB) is characterized by extreme events such as seasonal droughts and floods having different magnitudes. The precipitation regime has also been shifted from the south (dry alluvial plains of Sindh Province) to the north (Himalayan Mountains) part of the UIB. Conversely, flood events have been observed in the southern part of the UIB during the spring seasons [26].

Pakistan had faced severe types of drought events. Most of which occurred during the late 1960s, mid-
1980 s, late 1990 s, and early 2000 s. The drought event of 1998 had decreased agricultural growth by $2.6 \%$ between 2001 and 2002 [27]. The drought events of this region were classified as moderate (1969), severe (1998), and normal (2005), respectively. The worst drought spell of Pakistan's history was observed between 1999 and 2000 .

It has been observed an increasing trend in drought events during the last 12 years [28]. The drought spell of 2001-2002 resulted in a water shortage of up to $51 \%$ of normal supplies in contrast to $40 \%$ of the previous year. The drought spell of 2000 has also damaged the livestock of more than 30,000 in Sindh and Baluchistan provinces [29], and [30] considered this drought as vulnerable to Pakistan's economy. Moreover, Balochistan and Sindh provinces had experienced extreme meteorological conditions between 1961 and 1990, and these extreme drought events directly or indirectly affected a large population of this region [31]. The drought spell of 1993-2002 has directly or indirectly affected nearly $8,989,631$ peoples and lost 6,037 lives [32].

Pakistan is an agro-based country, and the survival of agriculture is reliant on water resources. The severe shortage of rainfall in Sindh, Balochistan, and South Punjab provinces caused drought events which resulted in water shortage and ultimately low economic activity in this region. The drought spell caused a huge loss of sheep, goats, cattle, horses, donkeys, camels, and poultry which was estimated up to Rs. 15 billion in the livestock sector [33]. Overall, the loss of financial assets estimated to (Rs.3.500 00 PKR) in Balochistan, (Rs.1.630 000) in Sindh, (Rs.4.400 000) in Khyber Pakhtunkhwa, and (Rs.5.500 000) in Punjab [34]. The previous history of drought events in Pakistan incites us to identify new trends and patterns of hydrological droughts in UIB. However, it is still unclear whether such recent, unprecedented events are part of spatiotemporal drought patterns that could be identified in historical streamflow observations.

Still, there is a lack of investigations on the spatiotemporal distribution of drought events, water scarcity, and duration. This situation requires using more accurate novel methods of innovative trends to enhance the analytical accuracy in data-scarce regions of the UIB, Pakistan. The main hindrance is the unavailability of historical hydrological information of the UIB in the way of understanding the pattern of hydrological drought events. Moreover, the streamflow gauging stations installed in remote areas are not easily accessible and have missing records of different seasons. [35] investigated the trends in drought events with respect to time distribution, return period, and extreme precipitation in UIB. There is still a lack of knowledge to understand the drought characteristics. So, the novel innovative trend (ITA) patterns were examined to precisely determine the trend pattern of hydrological drought for UIB which is a great source of water for agriculture and industry in Pakistan. 
Thus, the objectives of this study include to reveal the statistical characteristics of hydrological drought event's parameters and to detect the spatiotemporal trends in terms of duration and severity at different periods in UIB. So, the knowledge of the trend pattern of drought is essential to manage the inflows-outflows of dams and barrages located downstream of UIB. The outcomes of the current study will prove beneficial in managing regional water resources and to save the country's economy from possible loss.

\section{Study Area}

The part of the Indus basin above Mangla Dam is known as UIB. Gilgit, Hunza, and Kunhar are major tributaries of the UIB. The Mangla Dam receives $11 \%$ of the Kunhar River flow. Being in the Western Himalayas, the major part of the Kunhar basin lies at an altitude above $1500 \mathrm{~m}$ and its coordinates are $34^{\circ} \mathrm{N}$ and $74^{\circ} \mathrm{E}$ as presented in Fig. 1. The drainage area of the basin is approximately $2535 \mathrm{~km}^{2}$. It receives precipitation from the summer monsoon and winter westerlies. The seasonal precipitation shows two peaks in the part of the basin influenced by the monsoon while only one precipitation peak is detected in the part of the basin affected by the westerlies based on the analysis of the observed precipitation record of Naran meteorological station.

The Hunza River basin is greater than the Kunhar basin. The Hunza River basin has a drainage area of $13,713 \mathrm{~km}^{2}$ (Fig. 1), geographically extends from $36.05^{\circ} \mathrm{N}, 74.04^{\circ} \mathrm{E}$ to $37.08^{\circ} \mathrm{N}, 75.77^{\circ} \mathrm{E}$. It is located at the high-altitude of the central Karakoram region having a mean elevation of 4,631 m. Approximately 4,152 km² (or $30 \%$ ) of the catchment area is glaciated. The Hunza River carries the principal amount of water from May to September which is $90 \%$ of the total annual flow. The peak flow is generally observed in July.

The Gilgit River basin is another major tributary of UIB having a catchment area greater than Kunhar and less than the Hunza River basin. The Gilgit River basin with a drainage area of $13,471 \mathrm{~km}^{2}$ (Fig. 1) encompasses the eastern part of the Hindu Kush Range and drains southeastward into the Indus River. Gilgit River streamflows are measured at Gilgit and Alam Bridge hydrometric stations. Geographically, the basin extends from $35.80^{\circ} \mathrm{N}, 72.53^{\circ} \mathrm{E}$ to $36.91^{\circ} \mathrm{N}, 74.70^{\circ} \mathrm{E}$. The elevation of the basin ranges from 1250-7730 m a.s.1. Approximately $982 \mathrm{~km}^{2}$ (or $8 \%$ ) of the catchment area is above $5000 \mathrm{~m}$ elevation which is glaciated and it accounts for $4 \%$ of the UIB cryospheric extent [36]. Gilgit River basin also receives precipitation from both westerlies and Indian summer monsoon. The Gilgit River basin has 585 glaciers and 605 glacial lakes, whereas, out of 605 glacial lakes, 8 are potentially dangerous [37].

\section{Materials and Methods}

\section{Dataset}

The daily streamflow data collected from the Water and Power Development Authority (WAPDA), of

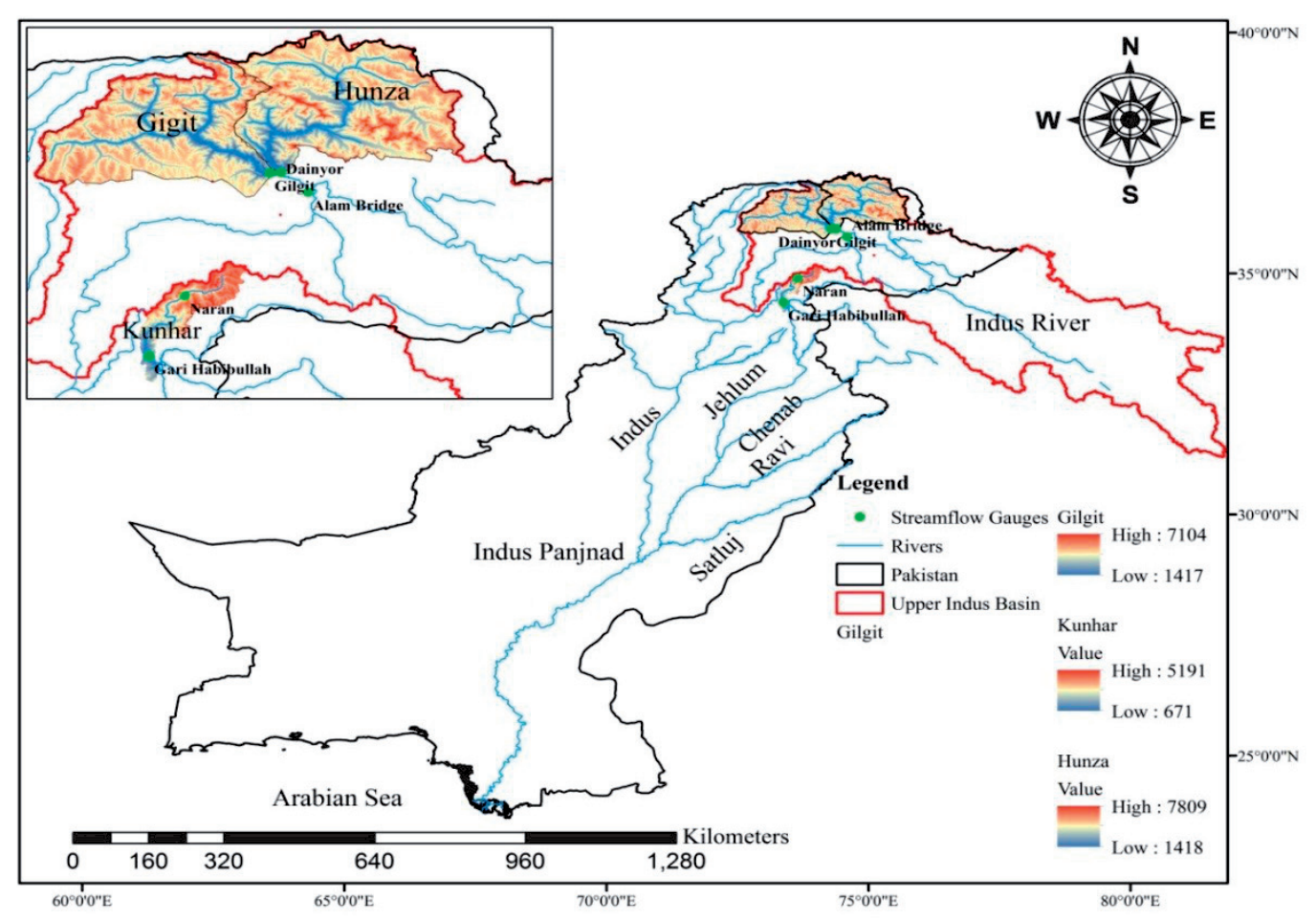

Fig. 1. Map of the study area. 
Table 1. List of streamflow gauging stations used in the current study.

\begin{tabular}{|c|c|c|c|c|}
\hline Sr. \# & Stations & $\begin{array}{c}\text { Latitude } \\
\left({ }^{\circ} \mathrm{N}\right)\end{array}$ & $\begin{array}{c}\text { Longitude } \\
\left({ }^{\circ} \mathrm{E}\right)\end{array}$ & Period \\
\hline 1 & Gilgit & 34.9 & 73.65 & $1961-2010$ \\
\hline 2 & Dainyor & 34.55 & 73.35 & $1966-2010$ \\
\hline 3 & Gari Habibullah & 34.40 & 73.38 & $1961-2010$ \\
\hline 4 & Naran & 34.91 & 73.65 & $1961-2010$ \\
\hline
\end{tabular}

Pakistan from 1961 to 2010 are presented in Table 1.

Criteria for the Selection of Threshold Value

Hydrological drought is defined using a threshold from the time series of a given station for a given period. A drought event is said to be the period during which the runoff is below the threshold level. Therefore, the role of the threshold value is important for defining the drought event. The past researchers used different thresholds to determine the drought event. Mostly, the median, mean, fixed threshold, and the variable threshold were being used to define the drought event. The threshold is defined as Q80 of flow values in flow duration curves. The drought event is defined as the threshold value greater than the mean value for the given period. After the threshold, the parameters of drought events are taken as drought duration and drought severity. Drought duration is the year, where streamflow is below the threshold level (D). The longest value of duration is called the annual maximum drought duration (AMD). Furthermore, the largest value of the severity is represented as the Annual Maximum Series (AMS). In this study, the minimum and inter-event duration were considered as 10 days. The current study eliminated minor drought events from the analysis by excluding events with durations of less than 10 days, similar to other researchers [38-40]. The diagram explaining the criteria for the selection of threshold levels for hydrological drought is displayed in Fig. 2.

\section{Sen's Innovative Trend Analysis}

Sen's innovative trend analysis (ITA) shows the five different types of trends i.e. monotonically positive, monotonically negative, non-monotonically increasing, and decreasing and no trend. The graphical procedure of ITA was described by [41]. ITA divides the time series into equal parts but does not identify the number of data values and their subgroups whereas the new method revealed its number of data and data groups. The $10 \%$ of bands are taken as:

$$
10 \% \text { confidence limit }=\mathrm{x} \mp 0.10 \times \bar{x}
$$

...where $\mathrm{x}$ and $\bar{x}$ represent the AMS or AMD and mean of the AMS or AMD, respectively. The basic two steps of the new method are the same as ITA. The time-series data is divided into two groups as given in Equation (2) and (3).

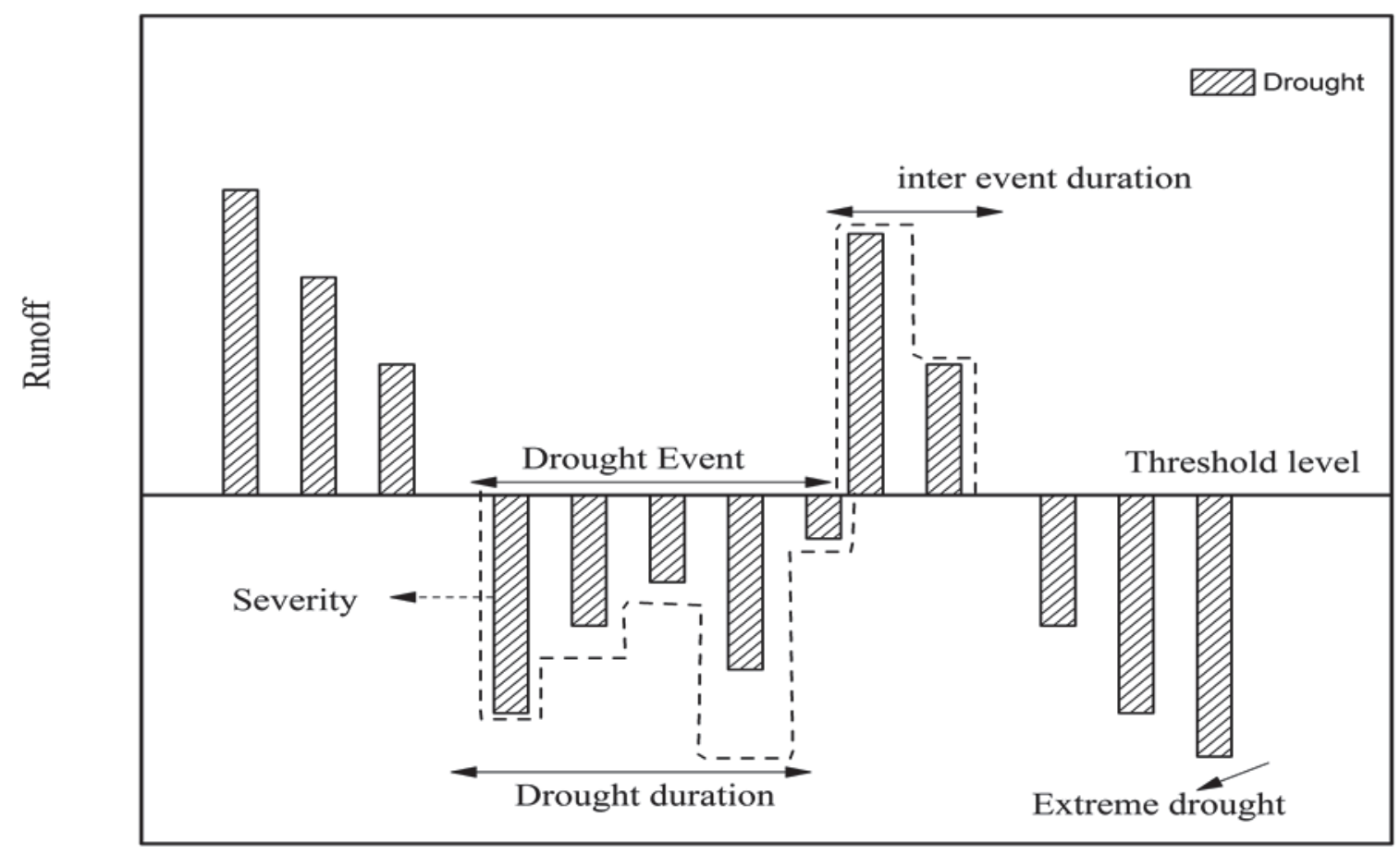

Time

Fig. 2. Sketch diagram showing the criteria for the selection of hydrological drought based on threshold levels. 
Table 2. Statistical analysis of scarcity for streamflows.

\begin{tabular}{|c|c|c|c|c|}
\hline Streamflow gauging stations & $\bar{X}\left(\mathrm{~m}^{3} / \mathrm{s}\right)$ & $\sigma\left(\mathrm{m}^{3} / \mathrm{s}\right)$ & $\mathrm{CV}$ & Median $\left(\mathrm{m}^{3} / \mathrm{s}\right)$ \\
\hline Gilgit & 702.99 & 499.10 & 0.71 & 732.50 \\
\hline Dainyor & 544.02 & 583.13 & 1.07 & 395.43 \\
\hline Garhi Habibullah & 315.73 & 211.77 & 0.67 & 298.05 \\
\hline Naran & 162.07 & 171.90 & 1.10 & 100.03 \\
\hline
\end{tabular}

$$
\begin{gathered}
S_{1}=\left[\min \left(d_{1, n / 2}\right), \ldots \ldots d_{i} \ldots \ldots \max \left(d_{1, n / 2)}\right]\right. \\
1<i<n / 2
\end{gathered}
$$

and

$$
\begin{gathered}
S_{2}=\left[\min \left(d_{2, n / 2}\right), \ldots \ldots d_{j} \ldots \ldots \max \left(d_{2, n / 2)}\right]\right. \\
1<j<n / 2
\end{gathered}
$$

Both time series are plotted on the vertical axis and the number of data values is plotted on the horizontal axis. Furthermore, the difference between $\mathrm{D}=s_{2}-s_{1}$ also plotted on the vertical axis against the number of data values. The difference of values falls on the horizontal line (trendless line) with random variations show that the trend is not significant. The difference line above the horizontal line represents a significantly increasing trend and below represents a significantly decreasing trend. In the end, the abrupt change is determined in both time series and difference between the series, which is defined as a subgroup. Before the change point, the value is lower and after the change point, the value is higher. The new illustration of ITA shows the number of data and its subgroups as low and high. The new ITA method has been used to evaluate the trends of hydrological droughts events in the UIB.

\section{Results and Discussions}

\section{Drought Analysis}

The drought analysis revealed the maximum value of water scarcity at Gilgit. The average scarcity of Dainyor was $23 \%$ lower as compared to Gilgit whereas Garhi Habibullah's average scarcity was found $49 \%$ higher than Naran. However, the Naran's average scarcity was found $540 \mathrm{~m}^{3} / \mathrm{sec}$ lower as compared to Gilgit (Table 2). The maximum deviation was found at Dainyor as compared to Naran, Gilgit, and Garhi Habibullah. The coefficient of variations of Naran and Dainyor was found to be similar as compared to Gilgit and Garhi Habibullah. The median of Gilgit was $46 \%$ higher than Dainyor. The median scarcity of Garhi Habibullah was $66 \%$ higher than Naran. Similar characteristics of scarcity were identified for Garhi Habibullah and Naran as well as Gilgit and Dainyor, respectively (Table 2).

The numbers of drought events were found to be similar at all stations except Garhi Habibullah. The mean duration of drought events at Gilgit and Dainyor was found to be similar. On the other hand, the duration of drought events in the Kunhar River basin (Naran and Garhi Habibullah) varied from 41 to 51 days. The maximum duration of drought events for Dainyor and Naran was found to be similar. The maximum duration of Garhi Habibullah was identified as $27 \%$ lower than Naran. The mean water deficit at Gilgit and Dainyor was observed higher than Garhi Habibullah and Naran (Table 3). The water scarcity at Gilgit was found to be $96 \%$ higher than Naran. The maximum deficit of Gilgit and Dainyor was found quite similar. The maximum deficit of Garhi Habibullah was increased by $52 \%$ from Naran. Mostly, the parameters of drought events for Gilgit and Dainyor were found to be similar whereas Garhi Habibullah and Naran showed different characteristics (Table 3).

\section{New Innovative Trend Pattern of Scarcity}

The spatial and temporal pattern of drought events was detected by new ITA analysis. The streamflow of three major tributaries of the UIB was analyzed. The hydrological droughts were categorized into different sub-categories such as light (less than 10\%), mild

Table 3. Summary of the different parameters of drought events.

\begin{tabular}{|c|c|c|c|c|c|}
\hline Stations & $\begin{array}{c}\text { Number of } \\
\text { events/year }\end{array}$ & $\begin{array}{c}\text { Mean Duration } \\
(\text { days })\end{array}$ & $\begin{array}{c}\text { Maximum Duration } \\
(\text { days })\end{array}$ & $\begin{array}{c}\text { Mean Deficit } \\
\left(\mathrm{m}^{3} / \mathrm{s}\right)\end{array}$ & $\begin{array}{c}\text { Maximum Deficit } \\
\left(\mathrm{m}^{3} / \mathrm{s}\right)\end{array}$ \\
\hline Gilgit & 1 & 65 & 124 & 7.17 & 58.73 \\
\hline Dainyor & 1 & 64 & 115 & 5.96 & 62.55 \\
\hline Garhi Habibullah & 2 & 41 & 86 & 3.95 & 19.30 \\
\hline Naran & 1 & 51 & 117 & 0.24 & 8.65 \\
\hline
\end{tabular}




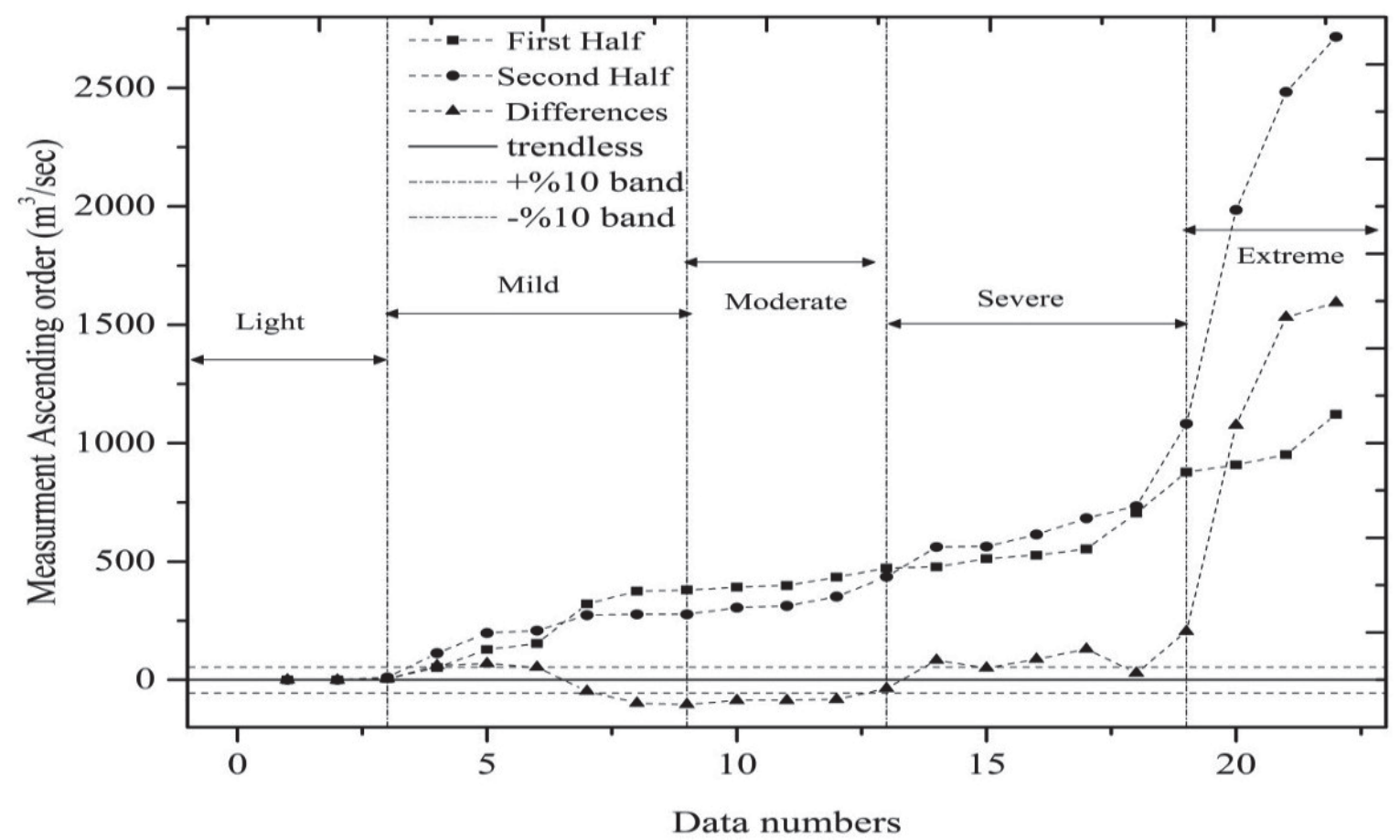

Fig. 3. New Innovative Trend Analysis (ITA) of Dainyor.

(10-40\%), moderate $(40-60 \%)$, severe $(60-90 \%)$, and extreme (greater than 90\%) [42]. For Dainyor, the light values of scarcity were found trendless. Similarly, the mild drought scarcity difference of both series was found to have a mixed trend and was insignificant. On the other hand, the first and second half series have a monotonic positive trend for mild drought scarcity (Fig. 3). The severity and extreme pattern of scarcity increased significantly for this region which indicates an alarming situation.

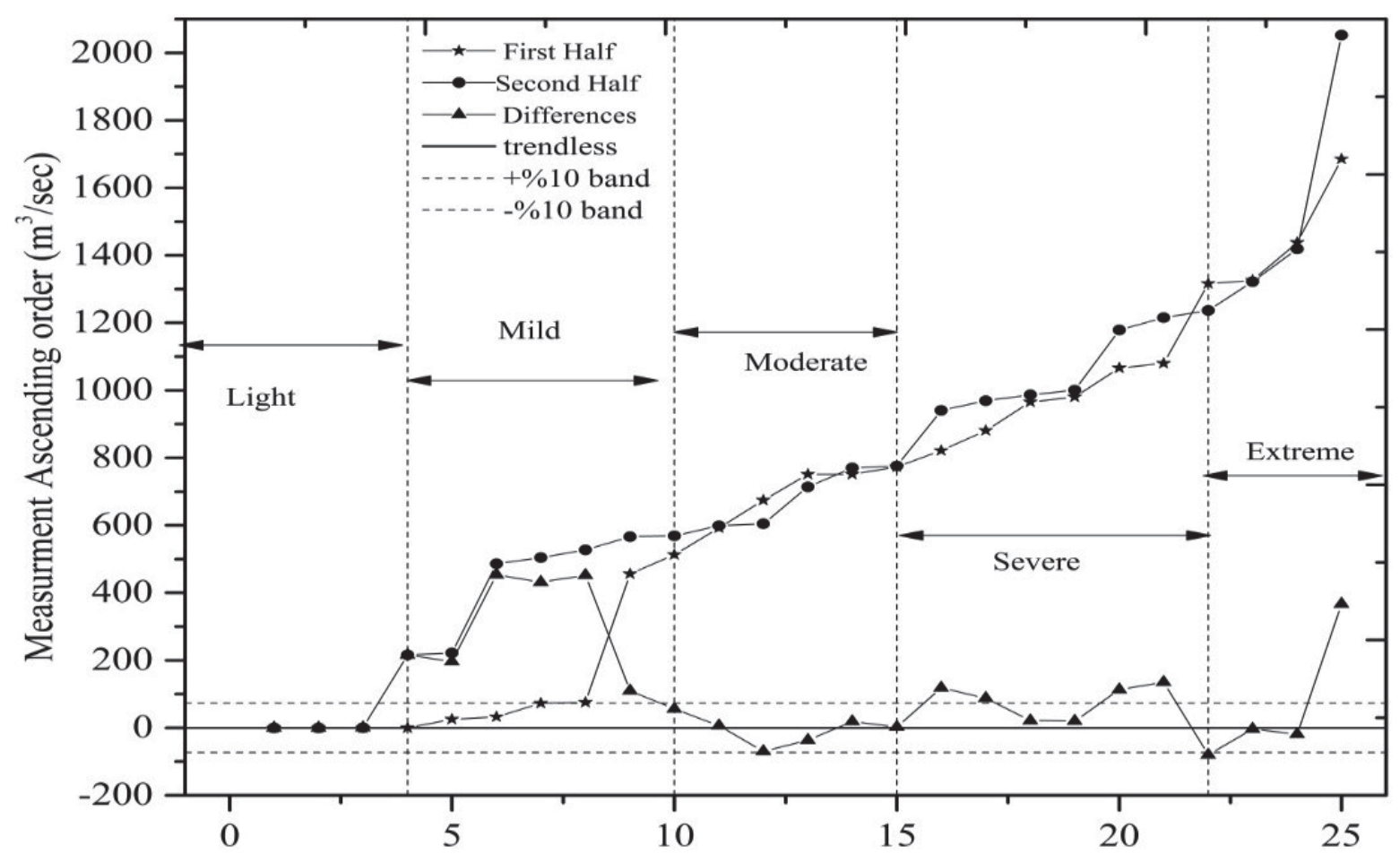

Data numbers

Fig. 4. New Innovative Trend Analysis (ITA) of Gilgit. 
Being the glaciered basin, the Hunza River basin under the impact of global warming is releasing more runoff mostly in the form of glacier melting which ultimately causes extreme events in this region. The Hunza River basin is facing drought and flood events at the same time in different seasons which ultimately causes an unusual pattern of streamflows in Hunza River. The ITA approach was used by [43] during the summer and winter seasons in eastern China. They identified increasing trends that confirm the risk management of floods and droughts in extreme seasons of this region.

Fig. 4 shows the pattern of hydrological drought for the Gilgit station. Fig. 4 shows that the difference of scarcity for two half periods has a significant decreasing trend for extreme range. The mild drought pattern displayed a significantly increasing trend, especially, at the mild and extreme range, whereas the moderate category displayed a decreasing trend (Fig. 4). Overall, the drought pattern of Gilgit showed an increasing but insignificant trend while the extreme class of drought exhibited a significantly increasing trend.

Fig. 5 shows the drought analysis at Garhi Habibullah using the new ITA method. It was observed a decreasing pattern of drought at Garhi Habibullah station. The light and severe classes have no trends while moderate and mild classes have a decreasing trend. However, the extreme class showed a significantly increasing trend. Overall, the difference in series for moderate scarcity decreased significantly at the $10 \%$ band. The average scarcity difference of the moderate class was $8.58 \mathrm{~m}^{3} /$ sec, which was $29 \%$ higher than mild and $64 \%$ than the light scarcity class. The severe drought pattern was observed about $11.70 \mathrm{~m}^{3} / \mathrm{sec}$ which was $36 \%$ lower than the extreme drought pattern (Fig. 5).

Fig. 6 shows the drought analysis at Naran using the new ITA method. The light pattern of drought displayed insignificant increasing trends whereas mild, moderate, severe, and extreme classes exhibited a significantly increasing trend. The drought difference series values in the extreme class were $84 \%$ higher than the mild class. The extreme class difference is $2.13 \mathrm{~m}^{3} / \mathrm{sec}$ higher than the severe class (Fig. 6).

\section{New Innovative Trend Pattern of Maximum Duration}

Fig. 7 showed that the light pattern of maximum duration increased significantly whereas the mild pattern decreased significantly at a $10 \%$ significance level at Dainyor. It was found that the moderate, severe, and extreme duration of drought pattern occurred in a trendless region within the $10 \%$ band. The first half time series of mild patterns found to be 20 days higher from the moderate pattern. The severe pattern of maximum duration was found 17 days higher than the moderate pattern of the first half time series. However, the extreme pattern was found to be $15 \%$ higher than the severe pattern of maximum duration (Fig. 7).

The light pattern of the maximum duration for Gilgit occurred in a trendless region as displayed in Fig. 8. The severe and extreme pattern of maximum duration was also found trendless at a $10 \%$ significance level. The moderate pattern of maximum duration displayed

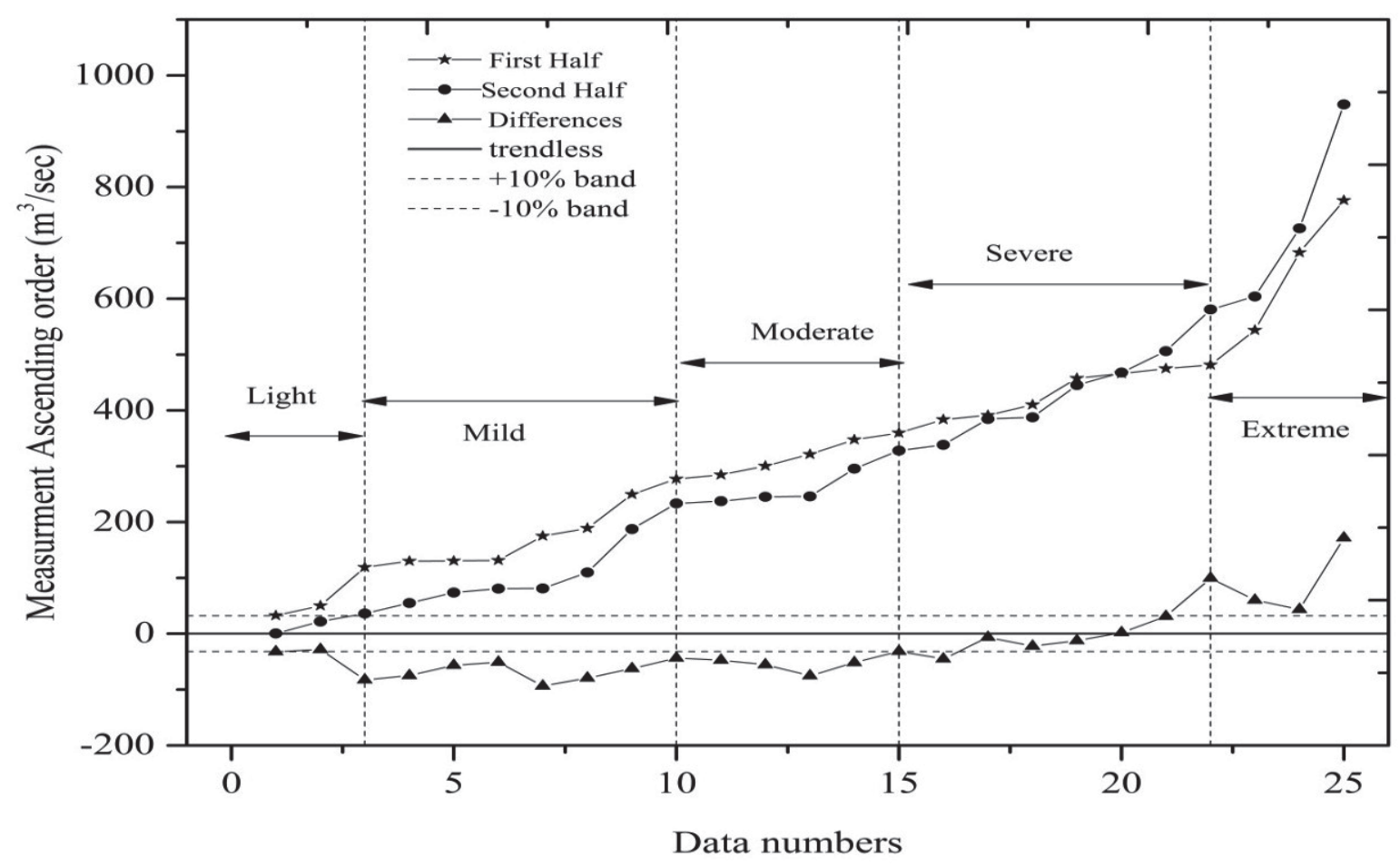

Fig. 5. New Innovative Trend Analysis (ITA) of Garhi Habibullah. 


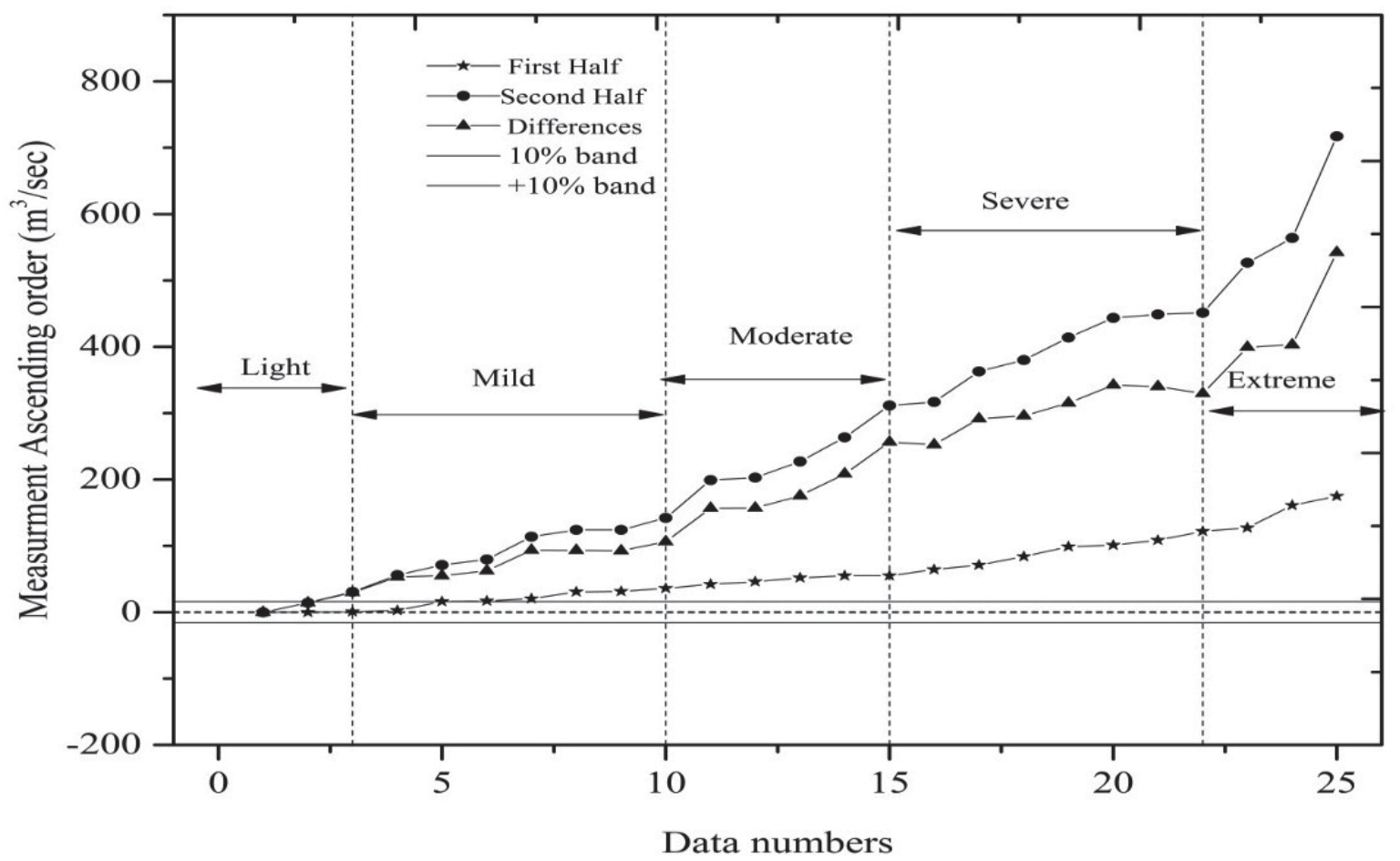

Fig. 6. New Innovative Trend Analysis (ITA) of Naran.

a decreasing trend. The mild pattern of maximum duration increased significantly at a $10 \%$ significance level. The moderate pattern of the maximum duration for the first half of the ascending series was found to be $38 \%$ higher than the mild pattern. The extreme pattern of maximum duration was found to be $19 \%$ higher than the severe pattern for the first-half series of maximum duration (Fig. 8).
The maximum duration pattern of drought events decreased significantly at Garhi Habibullah as presented in Fig. 9. The extreme pattern of maximum duration occurred in a trendless region. The maximum duration varied from 25 to 75 days for the light to extreme pattern. The mild pattern of maximum duration increased 16 days from the light pattern whereas the moderate pattern of maximum duration increased $25 \%$

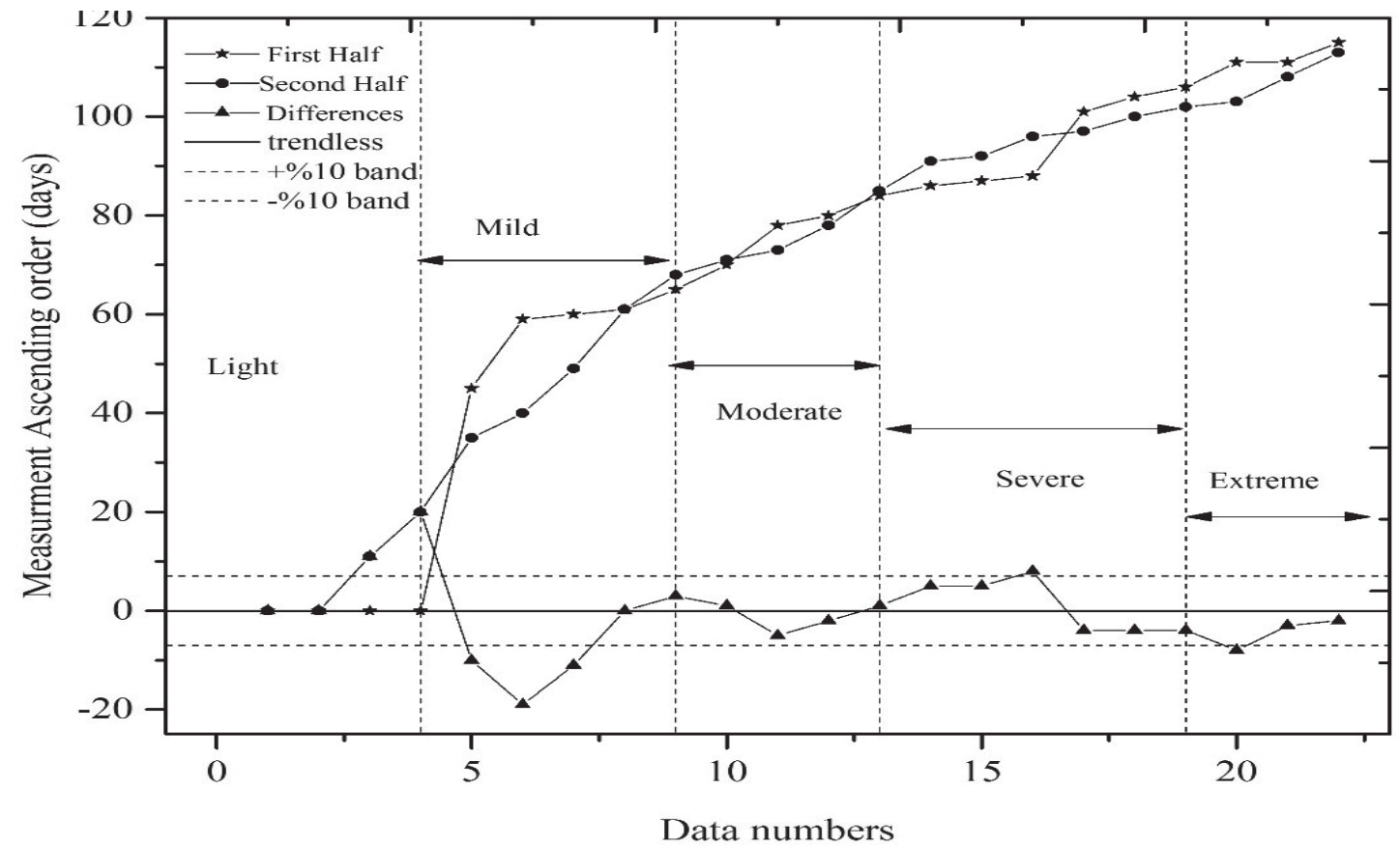

Fig. 7. New Innovative Trend Analysis (ITA) of the maximum duration of Dainyor. 


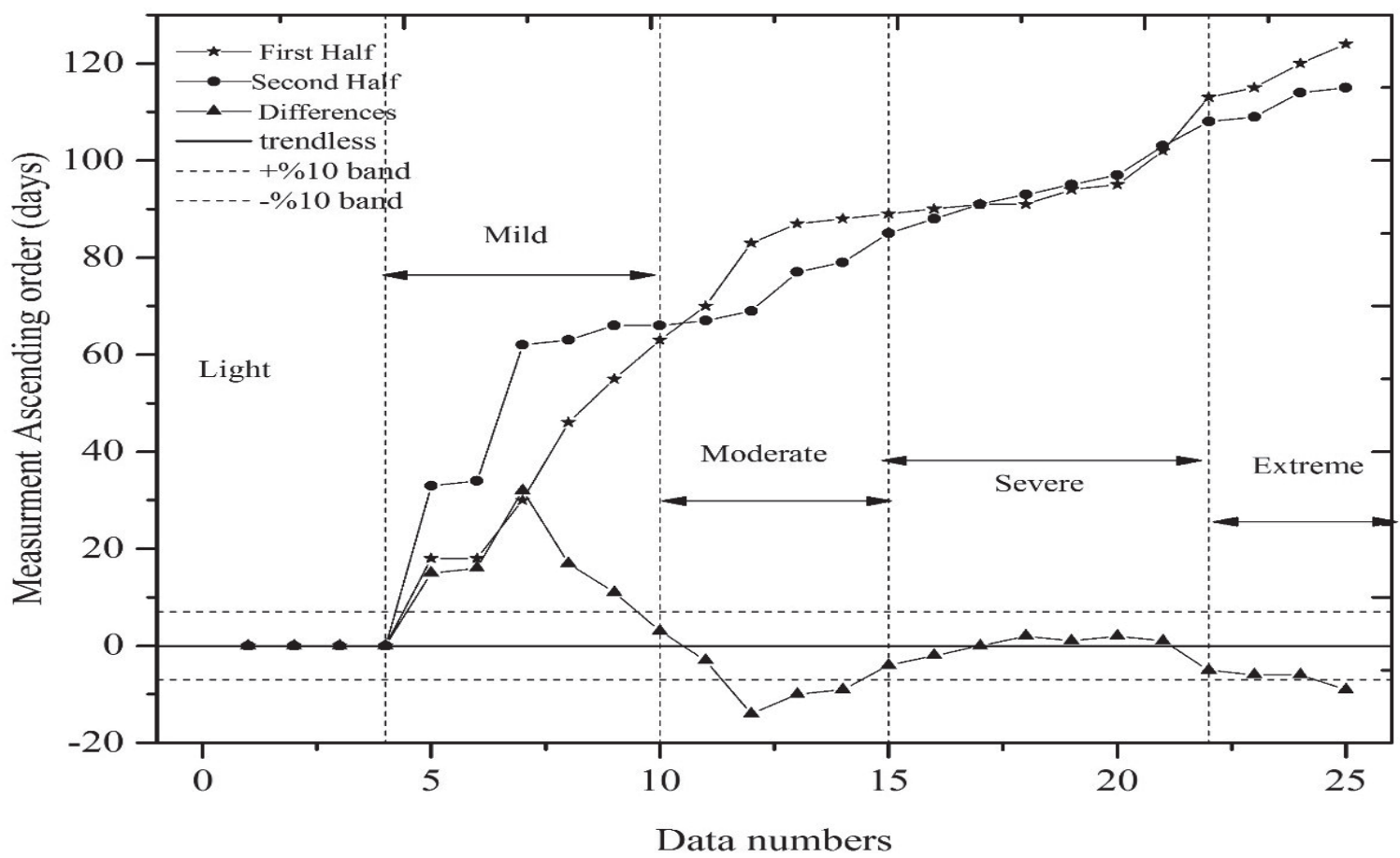

Fig. 8. New Innovative Trend Analysis (ITA) of the maximum duration of Gilgit.

from the mild pattern. The extreme pattern of maximum duration was found $13 \%$ higher than the severe pattern. Moreover, the moderate pattern of maximum duration was found 11 days lower than the severe pattern (Fig. 9).

The new ITA of the maximum duration for Naran is displayed in Fig. 10. The light pattern of maximum duration was found to be 29 days lower than the mild pattern. The light pattern occurred in the trendless region. The mild pattern of maximum duration increased significantly. The moderate, severe, and extreme patterns of maximum duration were found to be decreased significantly. The extreme pattern increased by $24 \%$ more than a severe pattern. On the other hand, the moderate pattern of maximum duration decreased $24 \%$ from the severe pattern. The mild pattern was

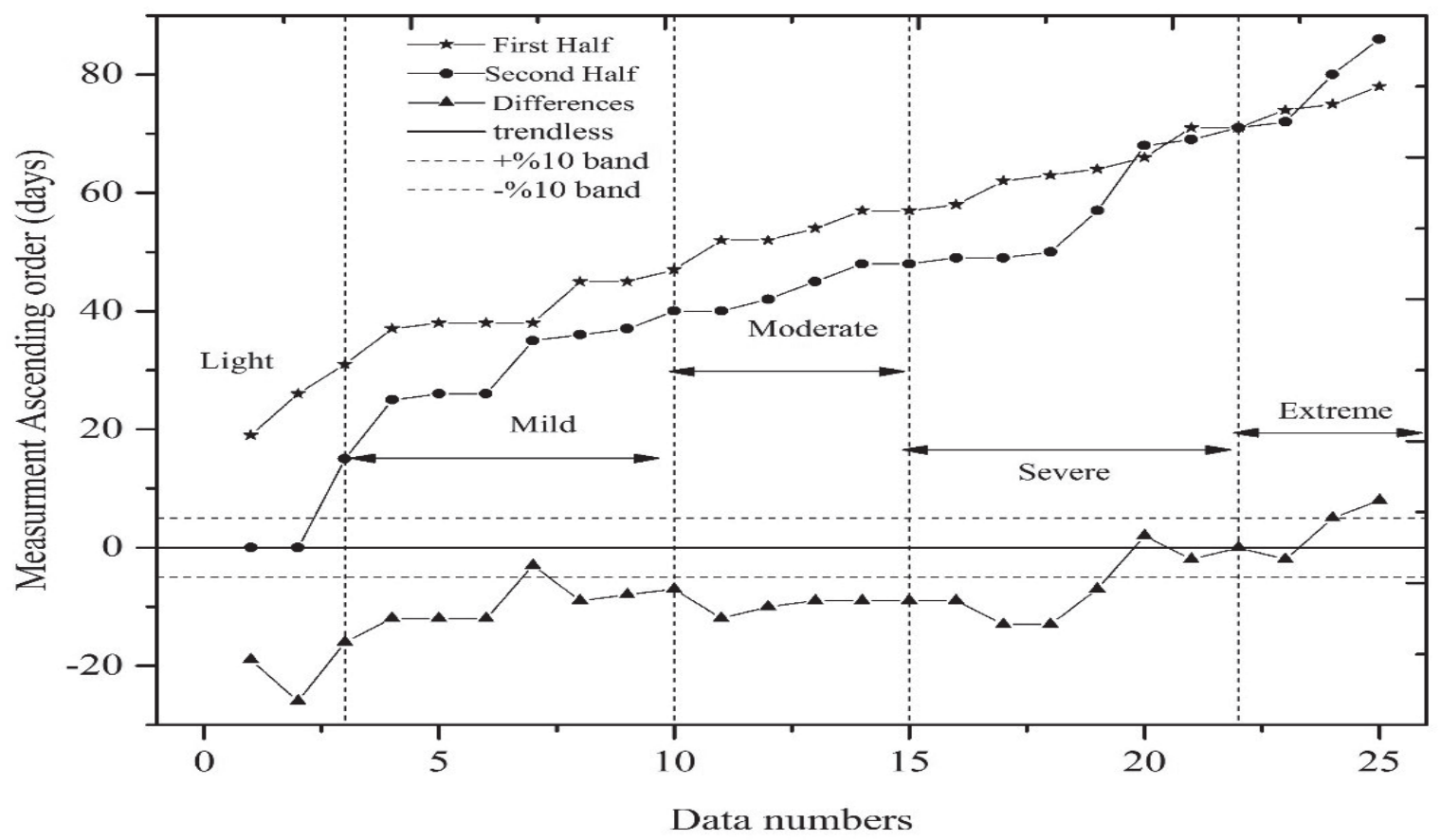

Fig. 9. New Innovative Trend Analysis (ITA) of the maximum duration of Garhi Habibullah. 


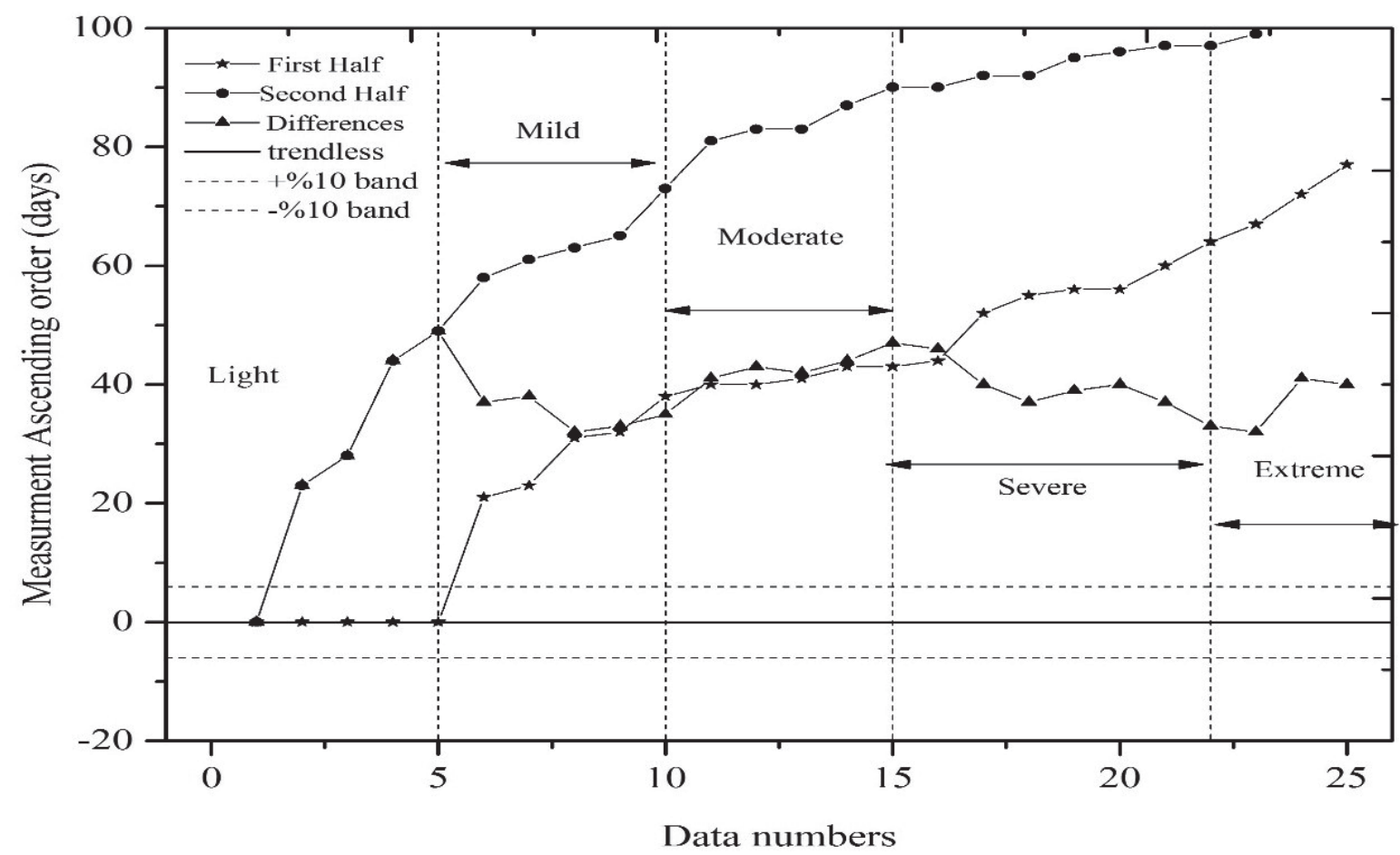

Fig. 10. New Innovative Trend Analysis (ITA) of the maximum duration of Naran.

found to be $29 \%$ lower than the moderate pattern of a maximum duration of the drought event. The extreme drought pattern showed a maximum duration of 72 days as compared to 29 days of the light pattern (Fig. 10).

\section{Discussions}

Natural disasters, especially, droughts are posing serious threats to Pakistan's society. The country is facing drought-like conditions once every six years. The droughts occur in any season, predominantly in summer as well as in winter for rainfed regions. Previously, no study was conducted to determine the drought pattern in this region which could be compared with our current study. However, [40] determined the threshold levels for identification of the droughts in the Kunhar River basin whereas another study conducted by [35] investigated the climate change influence on extreme events. The past studies did not determine the drought event intensity, scarcity, and maximum duration for this region. So, in the current study, the drought pattern with different intensities was evaluated and compared with the studies conducted in different parts of the world [39, 44, 45].

The results obtained in the current study generally agree with the findings of previous drought studies in Pakistan. [46] found the decreasing trend in water scarcity in Pakistan, which is consistent with our findings of Gilgit and Garhi Habibullah. The trends of extreme scarcity of Dainyor and Naran are significantly increasing and similar trends were found in Madeira and Tapajos River basin [7]. The moderate scarcity of Naran displayed an increasing trend and similar findings were observed in other parts of this region, specifically, in India. The moderate drought events were found to relatively more than extreme drought events in India [20]. It has also been reported that downstream of the Indus basin was severely affected by the drought [47]. [48] also reported the overall increasing trends of drought in Pakistan. The provincial analysis also displayed significant trends in drought events at Punjab, Sindh, and Khyber Pakhtunkhwa. The trends of the maximum duration for Gilgit, Dainyor, and Garhi Habibullah were found trendless, while trends of the maximum duration of drought for Naran were found to be significantly increasing. Similar findings were reported from the western part of the Himalaya (Pakistan) [40]. [49] reported the prolonged drought in Pakistan. Moreover, more frequent and extreme drought events were reported in South Korea [8]. The longer duration of the drought was also predicted in Malaysia due to the impact of climate change [19]. However, some differences were noted in this study. The trends of hydrological drought in Cyprus were found to be intensified with respect to time [44] and their results were slightly different from our findings. The study conducted by [50] observed a decreasing trend in spatial and temporal characteristics of hydrological drought, especially, during the last three decades in Iran. Similarly, [51] used the ITA method and found a decreasing trend in hydrological drought in the southeastern part of Turkey and also predicted a severe drought will hit this region in the near future.

The current study used a new ITA method for the investigation of drought patterns as compared to the 
traditional method. The current study determined the trend pattern for this region which was missing in previous studies. The study conducted by [26] determined the innovative trend analysis of precipitation for the UIB whereas the current study determined the drought scarcity and maximum duration of drought with New Innovative trend Pattern (NITP). The results suggest that the extreme pattern of drought scarcity increased significantly in this region. The maximum duration of droughts of the extreme pattern was found to be trendless except for Naran. Moreover, the findings also revealed that a possible extreme drought pattern of scarcity has increased while the maximum duration is reduced in different seasons. The increased frequency of hydrological drought events in the UIB will have severe impacts on the socio-economic life of the people living in this region. So, it is essential to monitor the trends of drought events with accuracy. Furthermore, a long-term assessment of the maximum duration of drought is required to manage the supply and demand of water resources in Pakistan. Hence, there is a need to pay close attention to drought management in different seasons to reduce the intensity and maximum duration.

\section{Conclusions}

The current study determined the hydrological drought conditions over the UIB in terms of streamflow variations using the new ITA (or threshold method) during 1961-2010. The different characteristics of hydrological droughts were determined for UIB. The water scarcity and maximum duration patterns were assessed for the given period. There is a clear pattern of drought events, water scarcity, and maximum duration; the basins where the occurrence of drought is more frequent have the maximum duration and vice versa. The results revealed that different intensities of drought events have a different pattern but the extreme pattern of drought increased significantly. These results depend on the threshold level and the minimum duration of drought events. The new ITA method identified the pattern of drought events scarcity and maximum duration.

The water scarcity at Dainyor was found to be trendless except for the extreme pattern, which increased significantly. The mild pattern of water scarcity of Gilgit was found to be increased significantly while other patterns occurred in the trendless region. The mild and moderate patterns of water scarcity decreased significantly for Garhi Habibullah while the extreme pattern was found to be increased. Overall, the scarcity pattern for Naran increased significantly. It was observed that the extreme pattern of scarcity has increased significantly in the UIB. The maximum duration of drought events at Naran increased significantly whereas it was not found a significant increase in the extreme pattern of maximum duration.
The extreme events duration is identified for a short duration as compared to a long duration.

The mild pattern of maximum duration decreased at Dainyor while it was increased at Gilgit station. All other patterns of maximum duration occurred in the trendless region. The maximum duration pattern of Garhi Habibullah decreased significantly except for extreme patterns. The findings of the maximum duration of drought events and scarcity patterns can be utilized for future planning of water resources management and food security of this region.

\section{Acknowledgements}

This study is supported by the NSFC-ICIMOD joint project (Grant no. 41761144075) and Yunnan University grant (2018M643541 and 209071). We are thankful to the Water and Power Development Authority (WAPDA) of Pakistan for providing the required information data.

\section{Conflict of Interest}

The authors declare no conflict of interest.

\section{References}

1. WITT J.L. National mitigation strategy partnership for building safer communities. Federal Emergency management agency Washington DC, 1995.

2. WITT J.L. National mitigation strategy: partnerships for building safer communities. Diane Publishing, 1997.

3. YU M., LI Q., HAYES M.J., SVOBODA M.D., HEIM R.R. Are droughts becoming more frequent or severe in China based on the standardized precipitation evapotranspiration index: 1951-2010? International Journal of Climatology, 34 (3), 545, 2014.

4. STRINGER L.C., AKHTAR-SCHUSTER M., MARQUES M.J., AMIRASLANI F., QUATRINI S., ABRAHAM E.M. Combating land degradation and desertification and enhancing food security: towards integrated solutions, $\mathbf{5 0}$, 1, 2011.

5. SOHRABI M.M., RYU J.H., ABATZOGLOU J., TRACY J. Climate extreme and its linkage to regional drought over Idaho, USA. Natural Hazards, 65 (1), 653, 2013.

6. ZHAO C., BRISSETTE F., CHEN J., MARTEL J.L. Frequency change of future extreme summer meteorological and hydrological droughts over North America. Journal of Hydrology, 584, 124316, 2020.

7. LOPES A.V., CHIANG J.C.H., THOMPSON S.A., DRACUP J.A. Trend and uncertainty in spatial-temporal patterns of hydrological droughts in the Amazon basin. Geophysical Research Letters, 43 (7), 3307, 2016.

8. BAE H., JI H., LIM Y.J., RYU Y., KIM M.H., KIM B.J. Characteristics of drought propagation in South Korea: relationship between meteorological, agricultural, and hydrological droughts. Natural Hazards, 99 (1), 1, 2019.

9. OLORUNTADE A.J., MOHAMMAD T.A., GHAZALI A.H., WAYAYOK A. Analysis of meteorological and hydrological droughts in the Niger-South Basin, Nigeria. Global and Planetary Change, 155, 225, 2017. 
10. SHARMA T.C., PANU U.S. Analytical procedures for weekly hydrological droughts: a case of Canadian rivers. Hydrological Sciences Journal-Journal des Sciences Hydrologiques, 55 (1), 79, 2010.

11. BATISANI N. Spatio-temporal ephemeral streamflow as influenced by climate variability in Botswana. Journal of Geographical Sciences, 21 (3), 417, 2011.

12. SHIAU J., FENG S., NADARAJAH S. Assessment of hydrological droughts for the Yellow River, China, using copulas. Hydrological Processes: An International Journal, 21 (16), 2157, 2007.

13. PEÑA-GALLARDO M., VICENTE-SERRANO S.M., HANNAFORD J., LORENZO-LACRUZ J., SVOBODA M., DOMÍNGUEZ-CASTRO F., MANETA M., TOMASBURGUERA M., EL KENAWY A. Complex influences of meteorological drought time-scales on hydrological droughts in natural basins of the contiguous Unites States. Journal of Hydrology, 568, 611, 2019.

14. KUBIAK-WÓJCICKA K., BĄK B. Monitoring of meteorological and hydrological droughts in the Vistula basin (Poland. Environmental Monitoring and Assessment, 190 (11), 691, 2018.

15. SKAKUN S., KUSSUL N., SHELESTOV A., KUSSUL O. The use of satellite data for agriculture drought risk quantification in Ukraine. Geomatics, Natural Hazards and Risk, 7 (3), 901, 2016.

16. CHEN Z., YANG G. Analysis of drought hazards in North China: distribution and interpretation. Natural Hazards, 65 (1), 279, 2013.

17. BORDI I., FRAEDRICH K., JIANG J.M., SUTERA A. Spatio-temporal variability of dry and wet periods in eastern China. Theoretical and Applied Climatology, 79 (1-2), 81, 2004.

18. ALAMGIR M., KHAN N., SHAHID S., YASEEN Z.M., DEWAN A., HASSAN Q., RASHEED B. Evaluating severity-area-frequency (SAF) of seasonal droughts in Bangladesh under climate change scenarios. Stochastic Environmental Research and Risk Assessment, 34 (2), 447, 2020.

19. TAN M.L., JUNENG L., TANGANG F.T., SAMAT N., CHAN N.W., YUSOP Z., NGAI S.T. SouthEast Asia HydrO-meteorological droughT (SEA-HOT) framework: A case study in the Kelantan River Basin, Malaysia. Atmospheric Research, 246, 105155, 2020.

20. MALIK A., KUMAR A., KISI O., KHAN N., SALIH S.Q., YASEEN Z.M. Analysis of dry and wet climate characteristics at Uttarakhand (India) using effective drought index. Natural Hazards, 1, 2020.

21. SADAT T., HOSSEINI M., HOSSEINI S.A., GHERMEZCHESHMEH B., SHARAFATI A. Drought hazard depending on elevation and precipitation in Lorestan, Iran. Theoretical and Applied Climatology, 142 (3), 1369, 2020.

22. DABANL İ., ZEKAI Ş., ÖNER M., EYÜP Ș., SELEK B., GÜÇLÜ Y.S. Trend assessment by the Innovative-Şen Method. Water Resources Management, 30 (14), 5193, 2016.

23. MADADGAR S., MORADKHANI H. Drought analysis under climate change using copula. Journal of Hydrologic Engineering, 18 (7), 746, 2011.

24. HAYHOE K., WAKE C.P., HUNTINGTON T.G., LUO L., SCHWARTZ M.D., SHEFFIELD J., WOOD E., ANDERSON B., BRADBURY J., DEGAETANO A., TROY T.J. Past and future changes in climate and hydrological indicators in the US Northeast. Climate Dynamics, 28 (4), 381, 2007.
25. KUMAR M.N., MURTHY C.S., SESHA M.V.R., ROY P.S. Spatiotemporal analysis of meteorological drought variability in the Indian region using standardized precipitation index. Meteorological Applications, 19 (2), 256, 2012.

26. AHMAD I., ZHANG F., TAYYAB M., ANJUM M.N., ZAMAN M., LIU J., FARID H.U., SADDIQUE Q. Spatiotemporal analysis of precipitation variability in annual, seasonal and extreme values over upper Indus River basin. Atmospheric Research, 213, 346, 2018.

27. AHMAD S., HUSSAIN Z., QURESHI A.S., MAJEED R., SALEEM M. Drought Mitigation in Pakistan: Current status and options for future strategies. International Water Management Institute, 85, 2004.

28. KHATTAK M.S., KHAN A., KHAN M.A., AHMAD W., SHARIF M., AHMAD S. Research article investigation of characteristics of hydrological droughts in Indus Basin. Sarhad Journal of Agriculture, 35 (1), 48, 2019.

29. PASHA M., ALI A., WAHEED A. Sindh drought 2014 Pakistan: was it a natural or a man-made disaster. Am J Soc Sci Res, 1 (1), 16, 2015.

30. SHEIKH M.M. Drought management and prevention in Pakistan. In COMSATS 1st meeting on water resources in the south: present scenario and future prospects, Islamabad, 1, 2001.

31. MAZHAR N., NAWAZ M., MIRZA A.I., KHAN K. Socio-political impacts of meteorological droughts and their spatial patterns in Pakistan. South Asian Studies, 30 (1), 2020.

32. WALTER J. World disasters report 2003: focus on ethics and aid. Kumarian Press Imprint, 2003.

33. ARBY M.F. State Bank of Pakistan: Evolution, functions and organization, 2004.

34. PALMER R., OXFAM G.B. Gendered land rights-process, struggle, or lost c (1) ause. Retrieved March 3 (2002), 2010.

35. ZAMAN M., AHMAD I., USMAN M., SAIFULLAH M., ANJUM M.N., KHAN M.I., UZAIR Q.M. Event-Based Time Distribution Patterns, Return Levels, and Their Trends of Extreme Precipitation across Indus Basin. Water, 12 (12), 3373, 2020.

36. HAYAT H., AKBAR T.A., TAHIR A.A., HASSAN Q.K., DEWAN A., IRSHAD M. Simulating Current and Future River-Flows in the Snowmelt-Runoff Model and RCP Scenarios. Water, 11 (4), 761, 2019.

37. SAIFULLAH M., LIU S., ADNAN M., ASHRAF M., ZAMAN M., HASHIM S., MUHAMMAD S. Risks of Glaciers Lakes Outburst Flood along China Pakistan Economic Corridor. In Glaciers and Polar Environment, IntechOpen, 2020.

38. RAZMKHAH H. Comparing threshold level methods in development of stream flow drought severity-durationfrequency curves. Water Resources Management, 31 (13), 4045, 2017.

39. RIVERA J.A., ARANEO D.C., PENALBA O.C. Threshold level approach for streamflow drought analysis in the Central Andes of Argentina: a climatological assessment. Hydrological Sciences Journal, 62 (12), 1949, 2017.

40. SAIFULLAH M., LIU S., TAHIR A.A., ZAMAN M., AHMAD S., ADNAN M., CHEN D., ASHRAF M., MEHMOOD A. Development of threshold levels and a climate-sensitivity model of the hydrological regime of the high-altitude catchment of the Western Himalayas, Pakistan. Water, 11 (7), 1454, 2019. 
41. ZEKAI S. Innovative trend significance test and applications. Theoretical and Applied Climatology, 127 (3-4), 939, 2015.

42. GAO L., ZHANG Y. Spatio-temporal variation of hydrological drought under climate change during the period 1960-2013 in the Hexi Corridor, China. Journal of Arid Land, 8 (2), 157, 2016.

43. WANG Y., XU Y., TABARI H., WANG J., WANG Q., SONG S., HU Z. Innovative trend analysis of annual and seasonal rainfall in the Yangtze River Delta, eastern China. Atmospheric Research, 231 (37), 104673, 2020.

44. MYRONIDIS D., IOANNOU K., FOTAKIS D., DÖRFLINGER G. Streamflow and hydrological drought trend analysis and forecasting in Cyprus. Water Resources Management, 32 (5), 1759, 2018.

45. YUAN X., WANG L., WU P., JI P., SHEFFIELD J., ZHANG M. Anthropogenic shift towards higher risk of flash drought over China. Nature communications, 10 (1), $1,2019$.

46. AHMED K., SHAHID S., CHUNG E.S., WANG X.J., HARUN S.B. Climate change uncertainties in seasonal drought severity-area-frequency curves: Case of arid region of Pakistan. Journal of Hydrology, 570, 473, 2019.

47. ALI S.M., KHALID B., AKHTER A., ISLAM A., ADNAN S. Analyzing the occurrence of floods and droughts in connection with climate change in Punjab province, Pakistan. Natural Hazards: Journal of the International Society for the Prevention and Mitigation of Natural Hazards, 1, 2020.

48. HINA S., SALEEM F. Historical analysis (1981-2017) of drought severity and magnitude over a predominantly arid region of Pakistan. Climate Research, 78 (3), 189, 2019.

49. NAZ F., DARS G.H., ANSARI K., JAMRO S. Drought Trends in Balochistan. Water, 12 (2), 470, 2020.

50. KAZEMZADEH M., MALEKIAN A. Spatial characteristics and temporal trends of meteorological and hydrological droughts in northwestern Iran. Natural Hazards, 80 (1), 191, 2016.

51. YILMAZ B. Analysis of hydrological drought trends in the GAP region (southeastern Turkey) by Mann-Kendall test and innovative sen method. Applied Ecology and Environmental Research, 17 (2), 3325, 2019. 